\title{
XXVIII. Note on Æther and motion
}

\section{Sir Oliver Lodge}

To cite this article: Sir Oliver Lodge (1919) XXVIII. Note on Æther and motion, Philosophical Magazine Series 6, 37:219, 315-315, DOI: 10.1080/14786440308635890

To link to this article: http://dx.doi.org/10.1080/14786440308635890

$$
\text { 册 Published online: } 08 \text { Apr } 2009 .
$$

Submit your article to this journal

LII Article views: 6

Q View related articles $\sqsubset$ 


\section{$\left[\begin{array}{ll}315 & ]\end{array}\right.$ \\ XXVIII. Note on Ather and Motion. By Sir Oliver Lodge*.}

R EFERRING to Dr. Houstoun's paper in the February 1 issue of the Phil. Mag., the supposition that the Ether of Spac can be in any sense attached to the body of the Earth involves so many fundamental difficulties that it cannot be considered an attractive hypothesis, and to my mind it has been definitely negatived by a series of rather elaborate experiments which I nade at Liverpool in the years 1892-7. See Phil. Trans. 1893, vol. 184, p. 727, and 1897, vol. 189, p. 149.

Possibly these papers have escaped Dr. Houstoun's attention. Taken in conjunction with the great experiment of Messrs. Michelson and Morley, the combined result definitely drives us to the view that the FitzGerald-Lorentz contraction-so probable on an electric theory of matter-is a reality.

Dr. Houstoun seems inclined to think that to admit this contraction is equivalent to admitting in full the negutions of the Principle of Relativity - not merely as a practically convenient summary for dealing with phenomena which otherwise would need detailed consideration, but as a law of nature. I do not myself feel in the least compelled to admit such a limitation, and hope that before very long some method of detecting and measuring the dirit of our solar and stellar system through the stationary $æ$ ther of space will be forthcoming. At any rate the door ought not to be prematurely shut on attempts in that direction, though the problem is admittedly a curious and unexpectedly difficult one: the compensations being so numerous and apparently so complete.

Incidentally I am glad to see, from his method of tackling the matter, thatDr. Houstoun agrees with me in holding that Fizean's experiment does not establish any motion of the æther of space inside a moving transparent medium: Fizeau's result, anticipated by Fresnel, definitely proves that the main body of Ether does not so move. All that moves with a stream of illuminated water is the retherial modification or loading which is responsible for lessening the velocity of light when travelling through a region occupied by matter. In other words, the thing that travels is the extra $K \mu$ which belongs to the matter, over and above the value of the product of these two fundamental retlerial constants in free space.

Would that it were possible to determine the ratio or some other function of these two constants, as well as their product! Then our knowledge of the Fther would indeed begin to forge ahead.

* Communicated by the Author. 